\title{
Evaluation of the frequency of patients with cancer presenting to an emergency department
}

\author{
Dem Isikber ${ }^{1}$ \\ (iD) Muge Gulen ${ }^{1}$ \\ (D) Salim Satar ${ }^{2}$ \\ (iD) Akkan Avci \\ (D) Selen Acehan ${ }^{1}$ \\ (iD) Gulistan Gul Isikber ${ }^{3}$ \\ (iD) Onder Yesiloglu'
}

1. Adana City Training and Research Hospital, Department of Emergency Medicine, Adana, Turkey. 2. Associate Professor, Adana City Training and Research Hospital, Department of Emergency Medicine, Adana, Turkey. 3. Adana City Training and Research Hospital, Department of Infectious Diseases and Microbiology, Adana, Turkey.

http://dx.doi.org/10.1590/1806-9282.66.10.1402

\section{SUMMARY}

OBJECTIVE: This study aims to determine the demographic characteristics of cancer patients admitted to an emergency department and determine the relationship between the frequency of admission to the emergency department and oncological emergencies and their effect on mortality.

METHODS: This observational, prospective, diagnostic accuracy study was performed in the ED of a tertiary care hospital. Patients over the age of 18 who were previously diagnosed with cancer and admitted to the emergency service for medical reasons were included in the study. We recorded baseline characteristics including age, gender, complaints, oncological diagnosis, metastasis status, cancer treatments received, the number of ED admissions, structural and metabolic oncological emergency diagnoses in the ED, discharge status, length of hospital stay, and mortality status.

RESULTS: In our study, 1205 applications related to the oncological diagnosis of 261 patients were examined. 55.6\% of the patients were male, and $44.4 \%$ were female. The most common metabolic oncological emergency was anemia (19.5\%), and the most common structural oncological emergency was bone metastasis-fracture (4.6\%.) The mean score of admission of patients to the emergency department was four times (min: 1 max: 29) during the study period. A total of 49.4\% (n: 129) of the patients included in the study died during follow-up, and the median time of death was 13 days after the last ED admission.

CONCLUSION: The palliation of patient symptoms in infusion centers that will be established in the palliative care center will contribute to the decrease in the frequency of use of emergency services.

KEYWORDS: Emergency Service, Hospital. Palliative care. Hospitalization. Neoplasms.

\section{INTRODUCTION}

Cancer is a severe disease that presents a physical burden as well as social, economic, and mental aspects'. It is observed that cancer patients present to emergency departments (ED) more frequently in the last six months before the death, primarily because of their decreased functional capacity, pain control deterioration, and changes in consciousness ${ }^{2}$. More than 4.5 million cancer patients annually present to 
EDs in the USA ${ }^{3}$. Cancer patients present to EDs due to the course of their oncological disease or complications related to their treatment. Due to many reasons such as increasing early diagnosis rates, increasing knowledge of patients about malignancy, changing treatment approaches, and prolonging follow-up periods, the life expectancy increases; thus, the number of cancer patients admitted to the emergency department increases too ${ }^{4}$.

This study aims to determine the demographic characteristics of cancer patients admitted to the emergency department and the relationship between the frequency of admission to the emergency department and oncological emergencies and their effect on mortality.

\section{METHODS}

This observational, prospective, diagnostic accuracy study was performed between July 01, 2016, and June 30, 2017, in the ED of a tertiary care hospital in Adana, Turkey. Patients over the age of 18 who were previously diagnosed with cancer and were under treatment (chemotherapy, radiotherapy) and admitted to the emergency service for medical reasons were included in the study. Patients with hematological malignancies (since there was no hematology specialist in our hospital at the time of the study), cancer patients admitted with trauma, and patients under 18 years old were excluded from the study. Ethics approval from the local ethics committee was obtained before the study process. A total of 1,205 emergency applications of 261 patients who met the inclusion criteria were examined. We recorded baseline characteristics including age, gender, complaints, the primary system involved (oncological diagnosis), metastasis status, cancer treatments received, the number of ED admissions, structural and metabolic oncological emergency diagnoses in the ED, discharge status, length of hospital stay, and mortality status. Patients were followed up regarding mortality throughout the study. Gender, age, treatments, oncological diagnosis, metastases, the number of ED admissions, and mortality status were evaluated according to the number of patients; other parameters were evaluated according to the number of applications. The primary outcome of the study was to determine the frequency of application to the emergency department and the outcome of cancer patients. The secondary outcome was to determine the structural and metabolic oncological emergencies that caused the patients' to apply to the emergency department.

\section{Statistical Analysis}

The data were analyzed with IBM V22 SPSS 5 . The appropriateness of quantitative measurements to normal distribution was examined by Shapiro-Wilk and Kolmogorov Smirnov tests. Mann Whitney U test and Kruskal Wallis test were used to compare the data with abnormal distribution. A chi-square test was used to analyze categorical data. Categorical data were presented as frequency (percentage), and quantitative data were presented as mean \pm deviation, and median (min-max). A p-value of $<0.05$ was set as the significance level.

\section{RESULTS}

In our study, 1205 applications related to the oncological diagnosis of 261 patients were examined. $55.6 \%(n=145)$ of the patients were male, and $44.4 \%$ $(n=116)$ were female. $60 \%(n=723)$ of the applications were from males, and $40 \%(n=482)$ were from female patients. The average age of women was $57.5 \pm 13.1$, while it was $63.3 \pm 12$ in men, and there was a statistically significant difference between the genders ( $p<0.001$ ). It was found that the most common reason for admission was related to the gastrointestinal tract (liver, gallbladder, pancreas, stomach, intestine). Considering the distribution by gender, the most common primary diagnosis was breast cancer in women $(17.6 \%, \mathrm{n}=46)$ and lung cancer $(19.5 \%, \mathrm{n}=51)$ in men. Metastasis was present in $36.4 \%$ ( $n=95$ ) of the patients (Table 1). The most common reason for ED admission was the progression of the disease in $53 \%(n=639)$ of the patients. $37.9 \%(n=457)$ of the patients applied to the ED with pain. Common body pain was the most commonly seen pain type with $14.6 \%(\mathrm{n}=176)$, and abdominal pain was present in $14.6 \%(n=176)$. When the frequency of admission of patients to the emergency department was evaluated, it was observed that the mean was four times (min: 1, max: 29) during the study period. $28 \%(n=73)$ of the patients had six or more admissions (Table 1).

There was no statistically significant relationship between the frequency of admission to the ED and the primary oncological diagnosis $(p=0.339)$. The median value of admission to the emergency department for patients with gynecological malignancy was significantly statistically different for patients with head 
TABLE 1. PATIENT DEMOGRAPHICS AND ADMISSION DETAILS

\begin{tabular}{|c|c|c|c|}
\hline & Female & Male & Total \\
\hline Gender n (\%) & $116(44.44)$ & $145(55.55)$ & $261(100)$ \\
\hline Age (yr, mean $\pm S D)$ (min-max) & $57.5 \pm 13.1(24-82)$ & $63.3 \pm 12(25-91)$ & $60.7 \pm 12.8(24-91)$ \\
\hline $\begin{array}{l}\text { Localization of malignancies } n(\%) \\
\text { Gastrointestinal } \\
\text { Lung } \\
\text { Breast } \\
\text { Genitourinary } \\
\text { Gynecological } \\
\text { Head and neck } \\
\text { Central nerve system } \\
\text { Lymphoma } \\
\text { Primary unknown } \\
\text { Skin }\end{array}$ & $\begin{array}{l}35(13.4) \\
11(4.2) \\
46(17.6) \\
2(0.8) \\
13(5.0) \\
1(0.4) \\
3(1.1) \\
3(1.1) \\
2(0.8) \\
0(0)\end{array}$ & $\begin{array}{l}40(15.3) \\
51(19.5) \\
3(1.1) \\
30(11.5) \\
0(0) \\
7(2.7) \\
5(1.9) \\
5(1.9) \\
3(1.1) \\
1(0.4) \\
\end{array}$ & $\begin{array}{l}75(28.7) \\
62(23.8) \\
49(18.8) \\
32(12.3) \\
13(5) \\
8(3.1) \\
8(3.1) \\
8(3.1) \\
5(1.9) \\
1(0.4) \\
\end{array}$ \\
\hline $\begin{array}{l}\text { Metastase n (\%) } \\
\text { Yes } \\
\text { No }\end{array}$ & $\begin{array}{l}36(13.8) \\
80(30.7)\end{array}$ & $\begin{array}{l}59(22.6) \\
86(33.0)\end{array}$ & $\begin{array}{l}95(36.4) \\
166(63.6)\end{array}$ \\
\hline $\begin{array}{l}\text { Cancer treatment } \\
\text { Chemotherapy } \\
\text { Radiotherapy } \\
\text { Chemotherapy and Radiotherapy }\end{array}$ & $\begin{array}{l}84(72.4) \\
3(2.6) \\
29(25)\end{array}$ & $\begin{array}{l}103(71) \\
3(2.1) \\
39(26.9) \\
\end{array}$ & $\begin{array}{l}187(71.64) \\
6(2.29) \\
68(26.25) \\
\end{array}$ \\
\hline $\begin{array}{l}\text { Number of presenting to the ED } \\
n(\%) \\
1 \\
2 \\
3 \\
4 \\
5 \\
\geq 6\end{array}$ & $\begin{array}{l}16 \\
26 \\
20 \\
18 \\
9 \\
27\end{array}$ & $\begin{array}{l}21 \\
25 \\
21 \\
17 \\
15 \\
46 \\
\end{array}$ & $\begin{array}{l}37(14.2) \\
51(19.5) \\
41(15.7) \\
35(13.4) \\
24(9.2) \\
73(28)\end{array}$ \\
\hline $\begin{array}{l}\text { Reason of ED visits n (\%) } \\
\text { Progressive disease } \\
\text { Chemotherapy effects } \\
\text { Infections } \\
\text { Radiotherapy effects }\end{array}$ & $\begin{array}{l}237(19.7) \\
202(16.8) \\
31(2.6) \\
12(1.0)\end{array}$ & $\begin{array}{l}402(33.4) \\
255(21.2) \\
58(4.8) \\
8(0.7)\end{array}$ & $\begin{array}{l}639(53) \\
457(37.9) \\
89(7.4) \\
20(1.7)\end{array}$ \\
\hline $\begin{array}{l}\text { Result of ED visits } \mathrm{n}(\%) \\
\text { Discharge from the ED } \\
\text { Hospitalization } \\
\text { Discharge } \\
\text { Mortality } \\
\text { Mortality at emergency department }\end{array}$ & $\begin{array}{l}364(30.2) \\
116(9.6) \\
108(9) \\
8(0.6) \\
2(0.2) \\
\end{array}$ & $\begin{array}{l}505(41.9) \\
213(17.7) \\
188(15.6) \\
25(2.1) \\
5(0.4) \\
\end{array}$ & $\begin{array}{l}869(72.1) \\
329(27.3) \\
296(24.6) \\
33(2.7) \\
7(0.6)\end{array}$ \\
\hline $\begin{array}{l}\text { Length of hospital stay } \\
\text { (day, mean } \pm \text { SD) }\end{array}$ & $6.8 \pm 6.3$ & $7.1 \pm 8.9$ & $7 \pm 8.1$ \\
\hline $\begin{array}{l}\text { Mortality } n(\%) \\
\text { Death during follow-up } \\
\text { Alive at end of follow-up }\end{array}$ & $\begin{array}{l}39(14.9) \\
77(29.5)\end{array}$ & $\begin{array}{l}90(34.5) \\
55(21.1) \\
\end{array}$ & $\begin{array}{l}129(49.4) \\
132(50.6)\end{array}$ \\
\hline
\end{tabular}

and neck cancer $(\mathrm{p}=0.007)$. Patients who were under chemotherapy were admitted to ED with an average of 3 times (min: 1, max: 18), while patients under radiotherapy had an average of 3 times (min: 1, max: 17). The average admission was four times for patients who received both treatments (min: 1, max: 29). There was no statistically significant difference between the frequency of admission to the ED and the received cancer treatment $(p=0.319)$. The patients who did not die during the study period were admitted to the ED with an average of 3 times (min: 1 max: 29), and the patients who died had an average admission of 4 times (min: 1, max: 22). There was no statistically significant difference between the frequency of admission to the ED and mortality $(p=0.100)$ (Table 2).
Metabolic oncological emergencies were detected in $71.9 \%(\mathrm{n}=866)$ of all the admissions. When metabolic oncological emergencies were evaluated, the most common hematological disorder was anemia with $19.5 \%(\mathrm{n}=236)$, while the most common biochemical disorder was hyponatremia with $5.1 \%$ $(n=61)$. There was a marginally significant effect between the presence of metabolic oncologic emergencies and the frequency of admission to the ED $(\mathrm{p}=0.050)$ (Table 3).

Structural oncological emergencies were detected in $15.4 \%(n=185)$ of all the admissions. The most common structural oncological emergencies in patients were fractures due to bone metastasis with $4.6 \%(n=56)$ and increased intracranial pressure (ICP) syndrome 
TABLE 2. THE RELATIONSHIP BETWEEN THE FREQUENCY OF PATIENTS PRESENTING TO EMERGENCY DEPARTMENT AND MORTALITY, PRIMARY CANCER DIAGNOSIS AND CANCER TREATMENT

\begin{tabular}{|c|c|c|c|}
\hline & \multicolumn{3}{|c|}{ The frequency of patients presenting to emergecny department } \\
\hline & Median (min-max) & Test statistics & $\mathrm{p}$ \\
\hline \multicolumn{4}{|l|}{ Primary cancer diagnosis } \\
\hline Head-neck & $7.5(3-15)$ & \multirow[t]{10}{*}{$\chi^{2}=22.528$} & \multirow[t]{10}{*}{0.339} \\
\hline Skin & $6(6-6)$ & & \\
\hline Lung & $4.5(1-29)$ & & \\
\hline Central nervous system malignancy & $4.5(1-17)$ & & \\
\hline Gastrointestinal system malignancy & $3(1-15)$ & & \\
\hline Breast & $3(1-15)$ & & \\
\hline Lymphoma & $3(1-15)$ & & \\
\hline Genitourinary system malignancy & $3(1-18)$ & & \\
\hline Gynecological & $3(1-5)$ & & \\
\hline Unknown primary & $1(1-5)$ & & \\
\hline \multicolumn{4}{|l|}{ Cancer treatment } \\
\hline Chemotherapy & $3(1-18)$ & \multirow[t]{3}{*}{2.285} & \multirow[t]{3}{*}{0.319} \\
\hline Radiotherapy & $3(1-17)$ & & \\
\hline Chemotherapy + Radiotherapy & $4(1-29)$ & & \\
\hline \multicolumn{4}{|l|}{ Mortality } \\
\hline Dead patients & $4(1-22)$ & \multirow[t]{2}{*}{$U=9507$} & \multirow[t]{2}{*}{0.100} \\
\hline Alive patients & $3(1-29)$ & & \\
\hline
\end{tabular}

Chi square test statistics, U: Mann Whitney U Test statistics

TABLE 3. DISTRIBUTION OF METABOLIC AND STRUCTURAL ONCOLOGICAL EMERGENCY DIAGNOSES ACCORDING TO THE FREQUENCY OF PATIENTS PRESENTING TO EMERGENCY DEPARTMENT

\begin{tabular}{|c|c|c|c|c|}
\hline & \multicolumn{4}{|c|}{ The frequency of patients presenting to emergecny department } \\
\hline & $n(\%)$ & Median (min-max) & Test statistics & $p$ value \\
\hline \multicolumn{5}{|l|}{ Metabolic Oncological Emergencies } \\
\hline Anemia & $236(19.58)$ & $6(1-29)$ & \multirow{14}{*}{$=25.280$} & \multirow{14}{*}{0.050} \\
\hline Thrombocytopenia & $136(11.28)$ & $6(1-29)$ & & \\
\hline Leukocytosis & $119(9.87)$ & $5(1-15)$ & & \\
\hline Febrile neutropenia & $64(5.31)$ & $5(1-14)$ & & \\
\hline Hyponatremia & $61(5.06)$ & $5(1-14)$ & & \\
\hline Hyperglycemia & $56(4.64)$ & $5(1-17)$ & & \\
\hline Leukopenia & $53(4.39)$ & $5(1-15)$ & & \\
\hline Hyperpotassemia & $30(2.48)$ & $6(1-18)$ & & \\
\hline Hypercalcemia & $28(2.32)$ & $4(1-15)$ & & \\
\hline Hypopotassemia & $23(1.90)$ & $6(2-12)$ & & \\
\hline Hyperuricemia & $19(1.57)$ & $6(1-29)$ & & \\
\hline Hypoglycemia & $17(1.41)$ & $5(1-15)$ & & \\
\hline Hypernatremia & $13(1.07)$ & $6(1-17)$ & & \\
\hline Hypocalcemia & $11(0.91)$ & $18(1-29)$ & & \\
\hline \multicolumn{5}{|l|}{ Structural Oncological Emergencies } \\
\hline Bone Metastasis-Fracture & $56(4.64)$ & $4(1-29)$ & \multirow{11}{*}{$\chi^{2}=15.310$} & \multirow[t]{11}{*}{0.121} \\
\hline Brain Metastasis-ICP syndrome & $41(3.40)$ & $4(1-29)$ & & \\
\hline Malignant Pleural Effusion & $25(2.07)$ & $6(2-15)$ & & \\
\hline Obstructive Uropathy & $19(1.57)$ & $6(1-18)$ & & \\
\hline lleus & $17(1.41)$ & $4(1-13)$ & & \\
\hline Malignant pericardial effusion & $8(0.66)$ & $5.5(1-14)$ & & \\
\hline Spinal Cord Compression & $5(0.41)$ & $4(2-4)$ & & \\
\hline Gastrointestinal Bleeding & $4(0.33)$ & $4.5(2-7)$ & & \\
\hline Vena Cava Superior Syndrome & $3(0.24)$ & $13(6-22)$ & & \\
\hline Pancreatitis-Hepatitis-Cholecystitis & $3(0.24)$ & $10(9-11)$ & & \\
\hline Airway Obstruction & $3(0.24)$ & $6(6-10)$ & & \\
\hline None & $1020(84.64)$ & - & - & - \\
\hline
\end{tabular}

$\chi^{2}$ : Chi square test statistics. ICP: Increased intracranial pressure 
due to brain metastasis with $3.4 \%(n=41)$. There was no statistically significant difference between the frequency of admission to the ED and the structural oncological emergencies ( $\mathrm{p}=0.121)$ (Table 3). Structural oncological emergencies were detected in $31.7 \%(\mathrm{n}=41)$ of patients who died during the study period and in $14.3 \%(\mathrm{n}=19)$ of patients who remained alive. There was a marginally significant effect between the presence of structural oncological emergencies and mortality. $(p=0.054)$

While $72.1 \%$ of the patients were discharged, $27.3 \%$ were hospitalized, and 0.6\% died in the ED (Table 1). $49.4 \%(n=129)$ of the patients included in the study died during the follow-up. $2.7 \%(\mathrm{n}=7)$ of the patients died in the $\mathrm{ED}$, and $12.6 \%(\mathrm{n}=33)$ died in the clinic where they were hospitalized; the median time for death was 13 days after the last ED admission.

The mean length of hospital stay was $7 \pm 8.1$ days for 329 admissions. There was no statistically significant difference between the length of hospital stay and the cancer treatment received $(p=0.272)$. There was no statistically significant difference between the length of hospital stay and metabolic oncologic emergencies $(p=0.259)$ and structural oncological emergen$\operatorname{cies}(\mathrm{p}=0.095)$.

\section{DISCUSSION}

In our study, we observed that cancer patients applied to the emergency department four times on average during the study, and $72.1 \%$ of all admissions resulted in discharge from the ED. Metabolic emergencies were detected in $71.9 \%$ of all admissions, and structural oncological emergencies in $15.4 \%$. There was no statistically significant effect of structural oncological emergencies and a marginally significant effect of metabolic oncological emergencies on the frequency of admission to the ED. There was no statistically significant difference between the frequency of admission to the ED and mortality.

Cancer is an increasing clinical health problem worldwide and leads to significant socioeconomic issues in communities and spiritual losses in individuals. Emergency admission of cancer patients may be related to oncological emergencies or other existing comorbidities due to the increased frequency of oldaged cancer patients. In both cases, it is life-threatening and has a high mortality. For this reason, early diagnosis and appropriate treatment in the ED are vital in reducing morbidity and mortality ${ }^{6}$.
According to 2018 data of GLOBOCAN, the three most common cancer types in men worldwide are lung cancer (31.5\%), prostate cancer (29.3\%), and colorectal cancers (23.6\%); in women, they are breast cancer (46.3\%), colorectal cancers $(16.3 \%)$, and lung cancer $(14.6 \%)^{7}$. Similar to the literature, in our study, we found that the most commonly seen cancer in men was lung cancer, and breast cancer in women. The most common complaints expressed to the emergency department are compatible with the three most common primary cancer etiologies (gastrointestinal malignancies, lung, and breast cancer). While abdominal pain, nausea, and vomiting were admission causes of gastrointestinal malignancies, the cause was dyspnea in lung carcinomas and metastasis in breast carcinomas.

Chronic widespread pain and fatigue complaints are thought to be due to systemic metastases, and anemia, both of which are common metabolic oncological emergencies. Anemia can occur due to primary cancer, as well as due to malnutrition or hemolysis and bone marrow infiltration caused by immunosuppressive treatments ${ }^{8}$. Hyponatremia, the most common biochemical impairment, can be seen due to cancer progression, inappropriate ADH syndrome, which is a paraneoplastic syndrome, side effects of chemotherapy, resistant vomiting, and low oral intake ${ }^{9}$. The most common metastasis occurs in the lungs, liver, and bones, respectively. Although all types of cancer can metastasize to the bone, $80 \%$ of bone metastases are primarily caused by prostate, breast, lung, kidney, and thyroid cancers ${ }^{10}$. Since the most common malignancies in the community are breast and lung cancers, we think that fracture due to bone metastasis is the most common structural oncological emergency.

Patients with oncological diseases are admitted to the ED due to the course of their existing malignancies (pressure symptoms, pain, bleeding, respiratory distress, etc.), indirect causes of the diseases (metabolic, endocrine, hematological, infectious, etc.), adverse effects of antitumor treatment (such as febrile neutropenia), or several acute problems caused by the patient's social conditions (such as lack of care and nutrition) $)^{11}$. In our study, 39.6\% of all admission was due to the side effects of the treatments (chemotherapy + radiotherapy). We think that outpatient units that will be established in chemotherapy units can help patients with pain management and provide symptomatic parenteral 
treatment. Also, the registration of cancer patients to a palliative care unit and follow-up of these patients by the palliative care team will reduce ED application of cancer patients ${ }^{12}$. With this solution, cancer patients who are also under immune suppression can be kept away from the emergency rooms that are the focus of a wide range of infectious agents. Also, we think that the intensity of the emergency department can be reduced by using emergency resources more effectively.

The frequency of admission to the emergency service in our study was higher than the other conducted studies in the literature ${ }^{13,14}$. It may be due to the fact that the study population consisted of patients in the active treatment period. According to the results of our study, the presence of metabolic oncological emergencies had a marginally significant effect on the frequency of emergency department admissions, whereas structural oncological emergencies had no statistically significant effect. This finding suggests that cancer patients were admitted to the ED instead of the primary care center or palliative care center for their simple complaints. As a result of advancing age and increased diagnostic possibilities, the incidence and follow-up time of oncological diseases have increased, and these patients apply to the emergency departments more than expected. The reasons for recurrent emergency admission were thought as follows: easy and faster accessibility to the ED, the fact that this group of patients did not want to wait in the outpatient queue for reasons such as chronic body pain, the emergency department services are available uninterruptedly, and the hospitalization of some of those patients from the outpatient clinic was delayed due to the lack of hospital rooms.

In studies, the rate of hospitalization in the general population was reported as $12-13 \%$ in ED of tertiary care hospitals ${ }^{15,16}$. In our study, $27.3 \%$ of all admissions were hospitalized. When assessed in comparison to all emergency admissions, the rate of hospitalization in oncological patients is high. Difficulties of care and low pain control for cancer patients at home are among the reasons for this high rate. According to other studies, ${ }^{17,18}$ the high rate of discharge from the emergency department can be explained by the absence of palliative care and infusion centers for pain palliation and symptomatic treatment. Problems that can be easily, cheaply, and quickly solved by family doctors and home care services in the places where patients live increase the burden of EDs. Also, hospitalization of these patients for pain palliation or parenteral fluid treatment alone is more harmful than beneficial due to hospital-acquired infections, deep venous thrombosis, etc. ${ }^{12}$

In one study, cancer patients' one-year mortality was determined as $39 \%$, and in another, the mortality rate was $70.6 \%^{14,19}$. In our study, the one-year mortality rate was $49.4 \%$, and the median duration until death after the last emergency admission was 13 days. Due to the deterioration of their general condition, frequent complaints, and psychosocial conditions, patients are admitted to emergency services that provide uninterrupted treatment and are easily accessible in the terminal period. EDs have great importance for cancer patients because, with the emergency department interventions, they can relieve their pain in the last stages of their lives and improve their quality of life. However, even if the emergency services provide medical support to cancer patients, they are insufficient for psychosocial and moral support due to their current patient loads. End-stage cancer patients need palliative care centers where their relatives can be with them before death. Also, in palliative care units, pain management, and additional treatments can be provided.

\section{CONCLUSION}

As a result, starting from the time of the definite diagnosis, follow-up of cancer patients by a team of oncologists, emergency specialists, family doctors, palliative care specialists, and other health care providers will help patients reach appropriate medical help in every stage of the disease. Home care service, palliative care, and effective use of the primary care system, and appropriate and sufficient care are vital for end-stage patients and increase the comfort of patients.

We think that the palliation of the symptoms that may occur in patients under active treatment period in infusion centers that will be established in chemotherapy units or in palliative care centers will contribute to the decrease in the frequency of emergency services.

\section{Financial support and potential conflict of interest}

This research did not receive any specific grant from funding agencies in the public, commercial, or not-for-profit sectors. The authors have no conflicts of interest to declare. 


\section{Acknowledgments}

None.

\section{Ethics Approval}

This study started after obtaining ethics approval from the T. C. Ministry of Health, Health Sciences University Adana Numune Training and Research Hospital Scientific Research Evaluation Commission.

\section{Author's Contribution}

Study concept and design: CI, MG, SS. Acquisition of data: CI, MG, GGI, AA, OY, SA. Analysis and interpretation of data: CI, MG, GGI, AA, OY. Drafting of the manuscript: CI, MG, SS, SA, AA. Critical revision: CI, MG, SS, GGI, OY, SA. All the authors approved the final version to be published; all authors agreed to all aspects of the work.

\section{RESUMO}

OBJETIVO: Este estudo tem como objetivo determinar as características demográficas dos pacientes com câncer admitidos no setor de emergência e determinar a relação entre a frequência de admissão no setor de emergência e emergências oncológicas e seus efeitos na mortalidade.

MÉTODOS: Este estudo observacional, prospectivo e de precisão diagnóstica foi realizado no pronto-socorro de um hospital terciário. Pacientes com idade superior a 18 anos que foram previamente diagnosticados com câncer e admitidos no serviço de emergência por razões médicas foram incluídos no estudo. Registramos características basais, incluindo idade, sexo, queixas, diagnóstico oncológico, status de metástase, tratamentos de câncer recebidos, número de admissões ao DE, diagnósticos de emergência oncológicos estruturais e metabólicos no DE, status de alta, tempo de internação e estado de mortalidade.

RESULTADOS: Em nosso estudo, foram examinadas 1205 aplicações relacionadas ao diagnóstico oncológico de 261 pacientes. 55,6\% dos pacientes eram do sexo masculino e 44,4\% eram do sexo feminino. A emergência oncológica metabólica mais comum foi anemia (19,5\%) e a emergência oncológica estrutural mais comum foi fratura óssea causada por metástase (4,6\%). A média de admissão dos pacientes no pronto-socorro foi de quatro vezes (min: 1 máx: 29) durante o período do estudo. Um total de 49,4\% (n: 129) dos pacientes incluídos no estudo morreram durante o acompanhamento, e a mediana para o tempo de morte foi de 13 dias após a última admissão ao ED.

CONCLUSÃo: A paliação dos sintomas de pacientes nos centros de infusão que serão estabelecidos nos centros de cuidados paliativos contribuirá para a diminuição da frequência de uso dos serviços de emergência.

PALAVRAS-ChaVE: Serviço Hospitalar de Emergência. Cuidados paliativos. Hospitalização. Neoplasias.

\section{REFERENCES}

1. Pimentel L. Medical complications of oncologic disease. Emerg Med Clin North Am. 1993;11(2):407-19.

2. McCarthy EP, Philips RS, Zhong Z, Drews RE, Lynn J. Dying with cancer: patients' function, symptoms, and care preferences as death approaches. J Am Geriatr Soc. 2000;48(S1):S110-21.

3. Rivera DR, Gallicchio L, Brown I, Liu B, Kyriacou DN, Shelburne N. Trends in adult cancer-related emergency department utilization: an analysis of data from the Nationwide Emergency Department Sample. JAMA Oncol. 2017;3(10):e172450.

4. Bozdemir N, Eray O, Eken C, Şenol Y, Artaç M, Samur M. Demographics, clinical presentations and outcomes of cancer patients admitted to the emergency department. Turk J Med Sci. 2009;39(2):235-40.

5. SPSS Inc. SPSS for Windows. Version 22.0. Chicago: SPSS Inc.; 2013.

6. Swenson KK, Rose MA, Ritz L, Murray CL, Adlis SA. Recognition and evaluation of oncology-related symptoms in the emergency department. Ann Emerg Med. 1995;26(1):12-7.

7. World Health Organization, International Agency Research on Cancer. Estimated number of new cases in 2018, worldwide, both sexes, all ages. [cited 2020 Feb 20]. Available from: URL: http://gco.iarc.fr/today/home

8. Madeddu C, Gramignano G, Astara G, Demontis R, Sanna E, Atzeni V, et al. Pathogenesis and treatment options of cancer related anemia: perspective for a targeted mechanism-based approach. Front Physiol. 2018;9:1294.

9. Sen F, Ciftci R, Erdemli HK, Kocabas R, Kılıc L, Yildiz I. The frequency of hyponatremia in oncology patients and possible association of hyponatremia with survival. J Turk Clin Biochem. 2014;12(1):37-43.

10. Mayadagli A, Bulut G, Ekici K. Approach to metastatic bone tumors. J Kartal TR. 2011;22(1):49-55

11. Higdon ML, Higdon JA. Treatment of oncologic emergencies. Am Fam Physician. 2006;11(74):1873-80
12. Caterino |M, Adler D, Durham DD, Yeung SI, Hudson MF, Bastani A, et al. Analysis of diagnoses, symptoms, medications, and admissions among patients with cancer presenting to emergency departments. JAMA Netw Open. 2019;2(3):e190979.

13. Tokocin O, Cakmak F, Ipekci A, Tihan DN, Ceylan D, Sutasir MN, et al. Factors affecting the morbidity and mortality of malignancy patients admitted to the emergency department. Phnx Med J. 2019;1(1):8-14.

14. Yaylaci S, Topuzoglu A, Karcioglu O. Clinical characteristics and one-year survival of cancer patients presenting to emergency department. Int J Hematol Oncol. 2009;19(4):213-22.

15. Aydın T, Aydın SA, Koksal O, Ozdemir F, Kulaç S, Bulut M. Evaluation of features of patients attending the emergency department of Uludag University Medicine Faculty Hospital and emergency department practices. JAEM. 2010;9(4):163-8.

16. Ersel M, Karcioglu O, Yanturali S, Yuruktumen A, Sever M, Tunç MA. Emergency Department utilization characteristics and evaluation for patient visit appropriateness from the patients' and physicians' point of view. Turk J Emerg Med. 2006;6(1):25-35.

17. Kerrouault E, Denis N, Le Conte P, Dabouis G. Improving organizastion of care could reduce referrals of cancer patients to the emergency department. Prospective analysis of 123 patients. Presse Med. 2007;36(11 Pt 1):1557-62.

18. Tanriverdi $O$, Beydilli $H$, Yildirim B, Karagoz U. Single center experience on causes of cancer patients visiting the emergency department in southwest Turkey. Asian Pac J Cancer Prev. 2014;15(2):687-90.

19. Koçak S, Ertekin B, Polat M, Girisgin S, Kara H. Reasons for oncology patients In the emergency department application. Sakaryamj. 2012;2(1):16-20. 